(C) 1982. The Genetical Society of Great Britain

\title{
ALTERED SALIVARY AMYLASE GENE IN THE MOUSE STRAIN BXD-16
}

\author{
J. PETER HJORTH \\ Department of Genetics, Aarhus University, Ny Munkegade, \\ DK-8000 Aarhus C, Denmark
}

Received 22.vii.81

\section{SUMMARY}

\begin{abstract}
An electrophoretic salivary amylase variant in the recombinant inbred mouse strain BXD-16 segregated in crosses as an allele at the salivary amylase locus. No other strain was found with the same combination of electrophoretic types of salivary and pancreatic amylase, and no sign of contamination by foreign genes from other strains was found. The variant therefore seems to have arisen during the inbreeding of the strain by a genetic alteration in the amylase complex.

Purified variant amylase had a lower heat stability and an altered net charge of one or more $\mathrm{CNBr}$ fragments, but had the same size distribution of peptides from restricted proteolysis and $\mathrm{CNBr}$ cleavage as salivary amylase from the progenitor strains. Radioactive pulse labelling of the variant amylase showed that its relative rate of synthesis was the same as that in the progenitor strains.

The variant is therefore, most likely, the result of a missense mutation that has altered the structure of all the salivary amylase produced in the strain. This indicates that only a single structural gene for the enzyme is expressed in the strain BXD-16.
\end{abstract}

\section{INTRODUCTION}

TissuE specific amylases in the house mouse (Mus musculus L.) are produced in the parotid glands and in the pancreas. The enzymes are genetically determined by two independent loci (Sick and Nielsen, 1964) localized close together on chromosome 3 (Nielsen and Sick, 1975; Eicher and Lane, 1980). This gene region is called the amylase complex (Hjorth, 1979) because recombination between the two loci has never been observed. The salivary amylase locus, $A m y-1$, probably contains a single structural gene because the protein structure of this amylase is homogenous in individual strains (Hjorth et al., 1980). Strains of mice can exhibit several different electrophoretic forms of pancreatic amylase and one, two, three or four banded patterns have been identified from individual strains (Hjorth et al., 1980). These strain specific patterns are inherited as units which are alleles of the pancreatic amylase locus $A m y-2$. These different forms of pancreatic amylase seem to have a unique primary structure and may therefore result from multiple structural genes in individual strains (loc. cit.).

Genetically determined differences in salivary and pancreatic amylase production are present among strains and the determinants for these characters are localized at Amy-1 (Hjorth, 1979) and Amy-2 (Bloor et al., 1981), respectively. For salivary amylase this variation seems to be caused by differences in regulatory elements whereas differences in copy numbers of the gene was inferred for the pancreatic amylase. Multiple pancreatic amylase genes were not found by molecular cloning of amylase mRNA from the strain A/J since only two unique sequences were revealed, one in the parotid glands and one in pancreas. For each of these sequences 
only one corresponding gene was demonstrated in the DNA of the A/J strain (Schibler et al., 1980; Hagenbüchle et al., 1980; Young et al., 1981). However, measurement of hybridizable amylase sequences in mouse DNA (Owerbach $e t$ al., 1981) revealed approximately 10 gene equivalents per haploid genome, i.e., 2.5 times more than in the rat in which at least four genes are present (MacDonald et al., 1980). This leaves the possibility open that different numbers of amylase structural genes could be active in different strains.

In the present report a salivary amylase variant in the recombinant inbred strain BXD-16 is described. The origin of this variant was traced through genetical and biochemical analyses. The results clearly do not favour the possibility that any other mouse strain could have provided the variant but support the idea that some genetic alterations have occurred during the inbreeding of the strain BXD-16. As the first potential case of a genetic alteration of the amylase complex in controlled breeding it provides an alternative way of obtaining insight into the amylase complex.

\section{MATERIALS AND METHODS}

\section{(i) Materials and animals}

Strains of mice, in addition to those kept at the Institute of Ecology and Genetics, University of Aarhus, were obtained from The Jackson Laboratory. The procedures used for preparing homogenates, determining amylase activity and protein, and obtaining samples of saliva from uninduced and isoproterenol induced mice have been described previously (Hjorth, 1979).

\section{(ii) Polyacrylamide gel electrophoresis (PAGE)}

Vertical slab gel electrophoresis was performed in an apparatus described previously (Hjorth, 1979). The standard native gel electrophoresis was performed using a tris-glycine, $p \mathrm{H} 8 \cdot 1$, system (Clarke, 1964) with six per cent acrylamide for $1 \mathrm{hr}$ at $100 \mathrm{~V}$ and then for $3 \mathrm{hrs}$ at $400 \mathrm{~V}$. Amylase activity was visualized and gels stained for protein as described previously (Hjorth et al., 1980).

To increase the resolution of salivary amylase isoenzymes, the standard PAGE procedure was modified as follows: The gel had eight per cent acrylamide, the electrode buffer was $p \mathrm{H} \mathrm{7.5}$ and electrophoresis was performed for $7 \mathrm{hrs}$ with the potential increasing from $200 \mathrm{~V}$ to $800 \mathrm{~V}$, keeping the current below $30 \mathrm{~mA}$ and the temperature at $5-10^{\circ} \mathrm{C}$. Best results were obtained with saliva samples obtained from isoproterenol induced mice.

Increased resolution of pancreatic amylase was obtained in a low $\mathrm{Cl}^{-}$ PAGE system modified from the standard procedure by adjusting the $p \mathrm{H}$ in gel- and electrode buffer to 9.0 and 8.5 respectively by $0.1 \mathrm{~N} \mathrm{NaOH}$. Both buffers had $1 \mathrm{mM} \mathrm{Cl}^{-}$added as $\mathrm{NaCl}$. This gel had four per cent acrylamide and $\frac{2}{3}$ of the standard tris and glycine content. Electrophoresis was performed for $8 \mathrm{hrs}$ with the potential increasing from $200 \mathrm{~V}$ to $700 \mathrm{~V}$, keeping the current below $30 \mathrm{~mA}$ and the temperature at $5-10^{\circ} \mathrm{C}$. For the analyses, 5-20 $\mu$ l supernatants were taken from pancreases that had been frozen in $0.1 \mathrm{ml} \mathrm{H} \mathrm{H}_{2} \mathrm{O}$, thawed, mixed, and centrifuged for $4 \mathrm{mins}$ at about $12,000 \mathrm{~g}$. 
(iii) Protein phenotypes of amylases

The procedures used for amylase purification, amylase heat inactivation, PAGE in the presence of dodecyl sulfate (SDS), isoelectric focusing, and digestion with $\mathrm{CNBr}$ and Streptococcus aureus protease have been described previously (Hjorth et al., 1980).

\section{(iv) Relative rate of synthesis}

Pulse labelling of mice with tritiated leucine was described by Hjorth (1979). Parotid glands from individual mice were homogenized in $1 \mathrm{ml}$ $0.05 \mathrm{M}$ phosphate buffer, $p \mathrm{H} 6.9$, containing $7 \mathrm{mM} \mathrm{NaCl}$ (buffer A). Homogenates were centrifuged for 10 mins at about $12,000 \mathrm{~g}$. To $1 \mathrm{ml}$ supernatant in a $1.5 \mathrm{ml}$ plastic test tube was added $50 \mu$ l slurry of sepharose 4B coupled with cyclohepta-amylose ( $\mathrm{CHA}$ ) prepared as described previously (Hjorth et al., 1980). After 10 mins gentle shaking and 5 mins at rest the supernatant was removed and the settled sepharose washed once with $0.5 \mathrm{ml}$ buffer $A$. The sepharose was then shaken with $50 \mu l$ buffer $A$ containing $8 \mathrm{mg} \mathrm{CHA} / \mathrm{ml}$ for $5 \mathrm{mins}$ to liberate the bound amylase. The whole purification procedure was carried out at $4^{\circ} \mathrm{C}$. This isolation procedure was not quantitative but the concentration of amylase in the final supernatants was found to be as high as $1 \mathrm{mg} / \mathrm{ml}$. As judged by analyses on PAGE in the presence of dodecyl sulfate this preparation contained no other proteins than amylase. $20 \mu \mathrm{l}$ of the preparation was subjected to the standard PAGE. The gel was stained for protein and dried on filter paper. 2-4 mm gel pieces were cut out and the radioactivity determined as described previously (Owerbach and Hjorth, 1980). The dividing line between radioactivity from the $A$ and the $B$ isoenzymes in heterozygotes was determined on the basis of the radioactivity distribution in reference lanes with either the A or the B enzyme alone. The presence of an anodally moving degradation band placed the dividing line close to the main $\mathrm{A}$ isoenzyme.

\section{RESUlts}

\section{(i) Inheritance of $S A L-B^{1.02}$}

Recombinant inbred (RI) strains are produced by inbreeding independent lines established from single pairs of $\mathrm{F} 2$ individuals from a cross between two established inbred strains, the progenitor strains. Individual RI lines therefore contain the genetic material from the two progenitor strains in variable proportions depending on the segregation and recombination that has taken place before complete homozygosity is established in the lines. However, in an investigation where saliva was used to determine the electrophoretic type of $P$ arotid secretory protein in the RI lines derived from C57BL/6J and DBA/2J (Hjorth, 1980), one strain, BXD-16 $(\mathrm{F}=40)$, had the electrophoretic salivary amylase type SAL-B, whereas SAL-A was found in both the progenitor strains and in 23 other BXD strains. The salivary amylase of the strain BXD-16 is called SAL-B ${ }^{1.02}$, the superscript indicating its slightly higher anodal electrophoretic mobility relative to the salivary amylase of the standard strain $\mathrm{C} 3 \mathrm{H} . A m y^{w 1}$ (fig. 1). Hybrids between BXD-16 and $\mathrm{C} 3 \mathrm{H} / \mathrm{As}$ had the two parental salivary amylase isoenzymes in about equal proportions, and among the offspring from intercrosses between such hybrids, 20 were SAL-A, 56 SAL-AB ${ }^{1 \cdot 02}$, and 
24 SAL- ${ }^{1.02}$. The electrophoretic type of pancreatic amylase is PAN-A for all 24 BXD strains and the progenitor strains whereas type PAN-B is found in the strain $\mathrm{C} 3 \mathrm{H} . A m y^{w 1}$ together with the salivary amylase type SAL- ${ }^{1 \cdot 00}$. In the $F 2$ generation of a cross between BXD-16 and C 3 H. Amy ${ }^{w 1} 35$ were SAL-B ${ }^{1.02}$ PAN-A; 74 SAL-B ${ }^{1.00} B^{1.02}$ PAN-AB, and 30 SAL- $B^{1.00}$ PAN-B. The obvious single factor segregation in this cross and the cosegregation of SAL- $\mathrm{A}^{1.02}$ with PAN-A suggest that the variant is determined by a new codominant allele, $A m y-1^{f}$, of the salivary amylase locus in the amylase complex $A m y^{\mathrm{BXD} 16}$. Amy- $1^{f}$ has been successfully transferred into a $\mathrm{C} 3 \mathrm{H} / \mathrm{As}$ strain background by 5 backcross generations, which indicate that no unusual amylase specific modifier genes are present in the BXD-16 genome.

A recessive variant gene on chromosome $4, d b^{4 J}$, which is not present in the progenitor strains has also been found in the strain BXD-16. This variant is genetically independent of the amylase variant, since no phenotypic interaction and independent assortment was demonstrated for the two loci in an F2 population of 187 mice.

\section{(ii) Origin of the genetic material in the strain BXD-16}

Although unlikely, it is possible that the strain BXD-16 by some error during the inbreeding had received genetic material from a foreign strain. At The Jackson Laboratory where the strain BXD-16 was established a total of 300 inbred strains were analyzed by the standard PAGE (Hjorth, 1980). One strain PERU-ATTECK/CamEi had the required haplotype SAL-B PAN-A. This type was found in one line besides the congenic PERU strain $\mathrm{C} 3 \mathrm{H} . A m y^{w 4}$, at the Genetic Department in Aarhus, namely in a $M . m$. castaneus line (with $A m y^{w 27}$ ) provided by V. Chapman, Buffalo, U.S.A. Prolonged electrophoresis of isoproterenol induced saliva revealed the amylase bands SAL-B ${ }^{1.00}$ and SAL- ${ }^{0.98}$ from $A m y^{{ }^{w 4}}$ and $A m y^{w 27}$, respectively, whereas the strain BXD-16 (as the only strain yet) had SAL-B ${ }^{1.02}$. To compare the pancreatic amylases a PAGE system with $p \mathrm{H} 9.0$ and $1 \mathrm{mM} \mathrm{Cl}^{-}$was used. Four different mobilities could be resolved in both the A and B regions (fig. 2b) but only one mobility class of $A$ and B protein was seen when $\mathrm{Cl}^{-}$was omitted from the buffers (fig. 2a). By the high resolution system the strain $\mathrm{BXD}-16$ was PAN-A ${ }^{1 \cdot 00}$, i.e., the same as C3H/As, C57BL/6J and DBA/2J. However, both C3H. Amy ${ }^{\text {w4 }}$, and the $M$. m. castaneus line with $A m y^{w 27}$ had patterns different from PAN-A ${ }^{1 \cdot 00}$ (fig. $2 b$ ). It was thus not possible to identify a strain with the same salivary and pancreatic amylase characteristics as the strain BXD-16.

The extensive allelic variation in the mouse suggests that if a foreign strain contaminated the strain BXD-16, other allelomorphs, which are not present in the progenitor strains, besides SAL- $B^{1.02}$ should have been found in that strain. Two pieces of evidence indicate that this is not so. First, during the typing of the 24 BXD RI lines for 29 loci (Taylor, 1981) no unexpected alleles or types were found for BXD-16 beside the $d b^{4 J}$ gene. Second, skin grafting from $B X D-16$ to $F 1$ hybrids between $C 57 \mathrm{BL} / 6 \mathrm{~J}$ and $\mathrm{DBA} / 2 \mathrm{~J}$ was performed by J. Klein, Tübingen. The grafts were not rejected within 157 days, indicating identity for both the $H-2$ and the many $H$-non 2 histocompatibility alleles. 


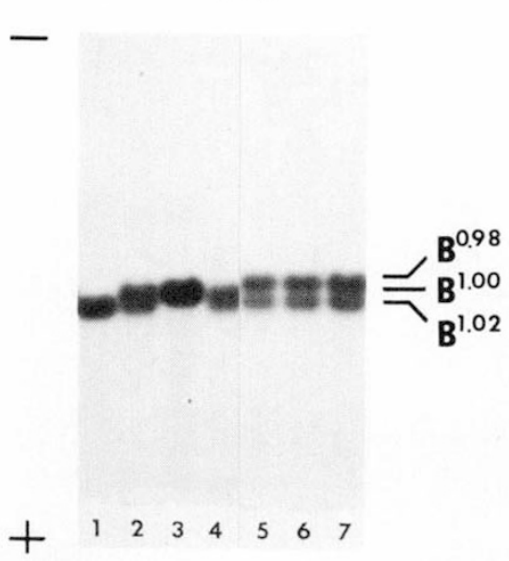

FIG. 1.-PAGE of isoproterenol induced saliva. The gel contained 8 per cent acrylamide, was electrophoresed for $7 \mathrm{hrs}$ at $200-700 \mathrm{~V}$ and stained for protein. Lanes 1-4 contain saliva from offspring of an intercross between hybrids of BXD-16 and C3H.Amy ${ }^{w 1}$. They were typed 1: SAL-B ${ }^{1.02}, 2$ and 4: SAL- $B^{1.00} B^{1.02}$, and 3: SAL-B ${ }^{1 \cdot 00}$. Lanes 5-7 contain saliva from hybrids between BXD-16 and the M. m. castaneus line with Amy ${ }^{\text {w27 }}$.
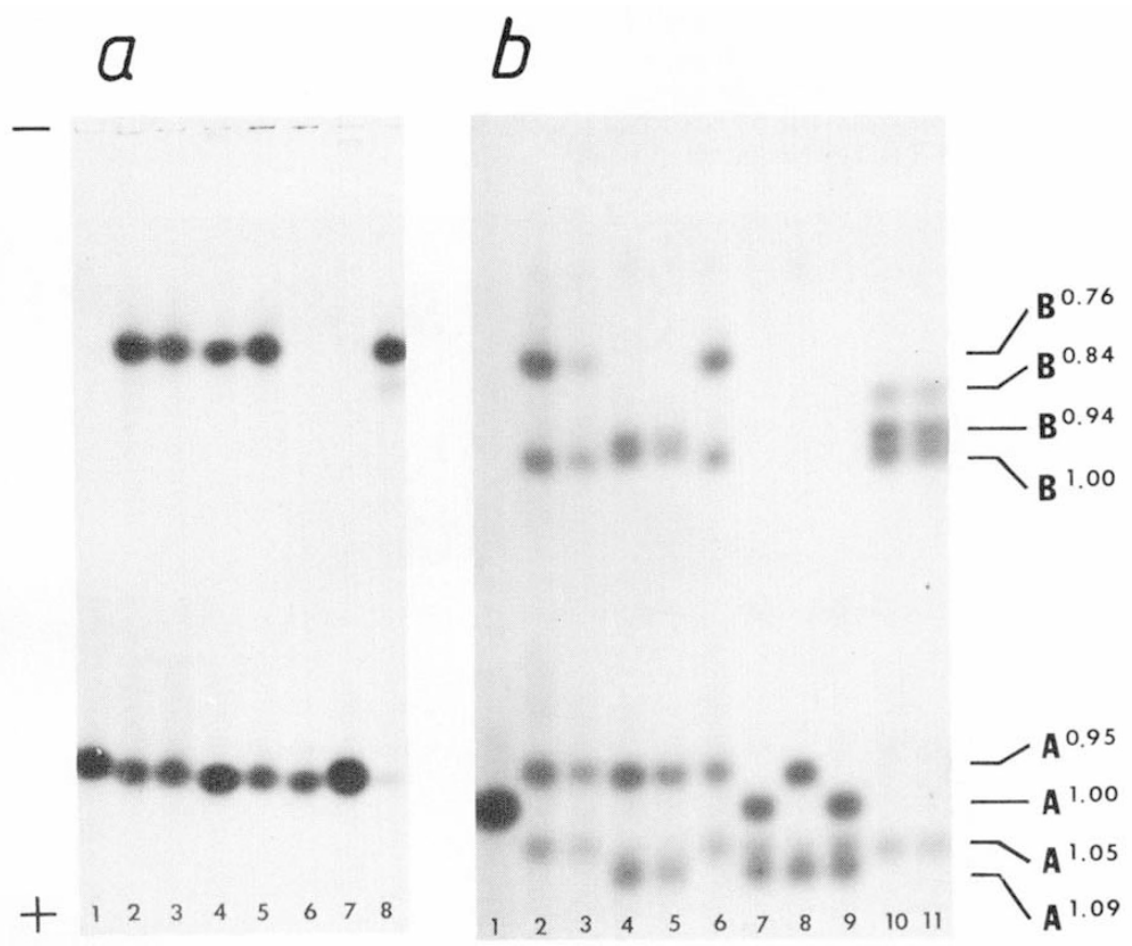

FIG. 2.-Pancreas extracts analyzed by PAGE in 4 per cent acrylamide gels with $p \mathrm{H} 9$ and $\frac{2}{3}$ of the standard tris and glycine content, electrophoresed for $8 \mathrm{hrs}$ at $200-700 \mathrm{~V}$. There was no $\mathrm{Cl}^{-}$in gel $a$ whereas $b$ had $1 \mathrm{mM} \mathrm{Cl}^{-}$. Both gels were stained for protein. Strains analyzed on gel $a$ were 1: $\mathrm{C} 3 \mathrm{H} / \mathrm{As}, 2: \mathrm{C} 3 \mathrm{H} . A m y^{C E}, 3: \mathrm{C} 3 \mathrm{H} . A m y^{w 3}, 4$ and 5: heterozygote of $\mathrm{C} 3 \mathrm{H} \cdot A m y^{w 1}$ and California, 6: $\mathrm{C} 3 \mathrm{H} . A m y^{w 4}, 7:$ heterozygote of $\mathrm{C} 3 \mathrm{H} / \mathrm{As}$ and $A m y^{w 27}, 8: \mathrm{C} 3 \mathrm{H} . A m y^{w 9}$. Strains on gel $b$ were 1: $\mathrm{C} 3 \mathrm{H} / \mathrm{As}, 2$ and 6 : $\mathrm{C} 3 \mathrm{H} . A m y^{C E}, 3: \mathrm{C} 3 \mathrm{H} . A m y^{w 3}, 4$ and 5: heterozygote of $\mathrm{C} 3 \mathrm{H} . A m y^{w 1}$ and California, 7 and 9: heterozygote of $\mathrm{C} 3 \mathrm{H} / \mathrm{As}$ and $A m y^{\mathrm{w} 27}, 8: \mathrm{C} 3 \mathrm{H} . A m y^{w 4}, 10$ and 11: $\mathrm{C} 3 \mathrm{H} . A m y^{w 9}$. For the purpose of nomenclature relative mobilities are used, the single PAN-A protein in $\mathrm{C} 3 \mathrm{H} / \mathrm{As}$ and the most anodal PAN-B protein in $\mathrm{C} 3 \mathrm{H} . A m y C E$ providing the standard units of mobility for each region. 


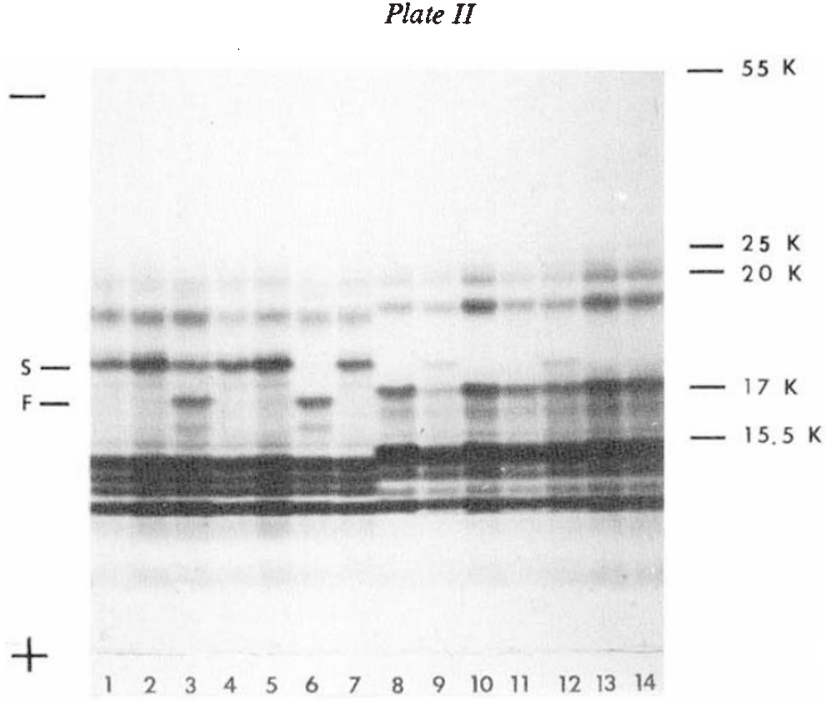

FIa. 3.- $\mathrm{CNBr}$ digests of salivary and pancreatic amylases analyzed by PAGE in a gel with 12 per cent acrylamide, 1 per cent SDS and $8 \mathrm{M}$ urea. Lanes 1 to 7 contain salivary amylase and lanes 8 to 14 pancreatic amylase from DBA/2J $(1,14), C 57 \mathrm{BL} / 6 \mathrm{~J}(2,13)$ a mixture of $\mathrm{C} 3 \mathrm{H}$. Amy ${ }^{\mathrm{YBR}}$ and BXD-16 $(3,12)$, a mixture of $\mathrm{C} 3 \mathrm{H} / \mathrm{As}$ and $\mathrm{BXD}-16$ $(4,11)$, BXD-16 $(5,10), \mathrm{C} 3 \mathrm{H} . A m y{ }^{Y B R}(6,9)$, and $\mathrm{C} 3 \mathrm{H} / \mathrm{As}(7,8)$. The molecular weight references were amylase $55 \mathrm{~K}$, chymotrypsinogen $25 \mathrm{~K}$, soybean trypsin inhibitor $20 \mathrm{~K}$, myoglobin $17 \mathrm{~K}$, and hemoglobin $15.5 \mathrm{~K}$.

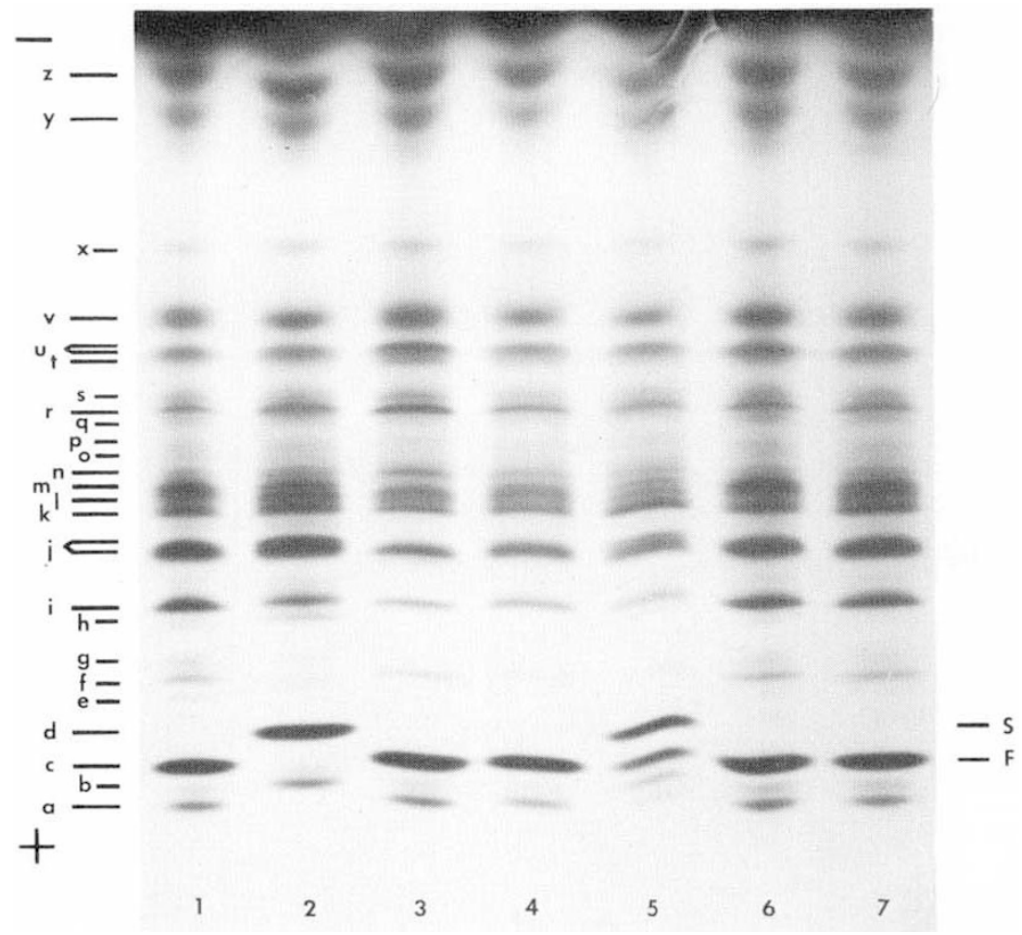

Fig. 4.- Isoelectric focusing of $\mathrm{CNBr}$ digests of salivary amylase. Lane 1: $\mathrm{C} 3 \mathrm{H} / \mathrm{As}, 2$ : $\mathrm{C} 3 \mathrm{H}$. Amy ${ }^{\mathrm{YBR}}$, 3: BXD-16, 4: a mixture of C3H/As and BXD-16, 5: a mixture of $\mathrm{C} 3 \mathrm{H} . A m y{ }^{\mathrm{YBR}}$ and BXD-16, 6: C57BL/6J, 7: DBA/2J. 


\section{(iii) Protein structure analysis of the variant amylase}

The structure of the amylases of the strain BXD-16 were studied in order to clarify whether there may have been an amino acid substitution resulting from a single missense mutation in the genetic information for salivary amylase. Such an explanation is suggested by the lower anodal electrophoretic mobility of SAL-B ${ }^{1.02}$ relative to SAL-A. Also the similar 0.3 units increased $p I$ of $S A L-B^{1.02}, S A L-B^{0.98}$, and SAL-C relative to SAL-A indicates that this increment represents the loss or the gain of one electrical charge unit. Salivary and pancreatic amylases were purified from the strains BXD-16, C57BL/6J, DBA/2J, C3H/As, and C $3 \mathrm{H} . A m y{ }^{\mathrm{YBR}}$ using the previously described affinity chromatography technique (Hjorth et al., 1980). A single protein band was seen by the standard PAGE for salivary amylase purified from the strain BXD-16. This protein had the same apparent molecular weight as that of $\mathrm{C} 3 \mathrm{H} / \mathrm{As}$ when analyzed by PAGE in the presence of SDS, and it had also the same catalytic activity per protein unit.

Many similarities were found between the purified amylases of BXD-16 and the progenitor strains, whereas differences only were found in salivary amylase with respect to heat stability and the isoelectric focussing (IEF) patterns of $\mathrm{CNBr}$ digests (table 1). In the IEF patterns (fig. 4) a new band $n$ was present in both the digests of the pure protein from BXD-16 and the digests of mixtures of this protein and either $\mathrm{C} 3 \mathrm{H} / \mathrm{As}$ or $\mathrm{C} 3 \mathrm{H}$. Amy ${ }^{\text {YBR }}$ salivary amylase. A clear but less apparent intensity increase of peptides $r$ and $u$ and decrease in peptides $i$ and $j$ is seen indicating that three peptides may have shifted to a less negative net charge. It is, however, possible that these three peptides are $f$. inst. deamidation derivatives of the same primary $\mathrm{CNBr}$ fragment that in turn has a net charge one negative unit lower than the corresponding fragment of SAL-A.

The protein structure of salivary amylase from the strain BXD-16 as revealed here has many similarities to the enzyme in $\mathrm{C} 57 \mathrm{BL} / 6 \mathrm{~J}$ and $\mathrm{DBA} / 2 \mathrm{~J}$. The differences in electrophoretic mobility, heat stability, and pI of peptides produced by $\mathrm{CNBr}$ digestion, can all be explained as the result of a single amino acid substitution leading to a charge change. None of the alterations in protein structure is reflected in alterations of the pancreatic amylase structure.

\section{(iv) Relative rate of synthesis of $S A L-B^{1 \cdot 02}$}

The relative amounts of SAL-B ${ }^{1.02}$ in saliva of heterozygotes between the BXD-16 strain and the progenitor strains were determined as previously described (Hjorth, 1979) by scanning the amylase isoenzymes in protein stained PAGE separations of isoproterenol induced saliva (table 2). In addition, the relative rate of synthesis of SAL- $B^{1 \cdot 02}$ was determined by in vivo pulse labelling of the same kind of heterozygotes with ${ }^{3} \mathrm{H}$-leucine. After PAGE of amylase purified from glands of individual mice the radioactivity in the two isoenzymes was measured. The mean values of the relative amount and rate of synthesis of the B isoenzyme were close to 0.5 (table 2). Since this is the expected value in heterozygotes between alleles with the same expression, it is apparent that the same production rate of salivary amylase is determined by the alleles in the strain BXD-16 and the strains C57BL/6J, DBA/2J, and C3H/As. 


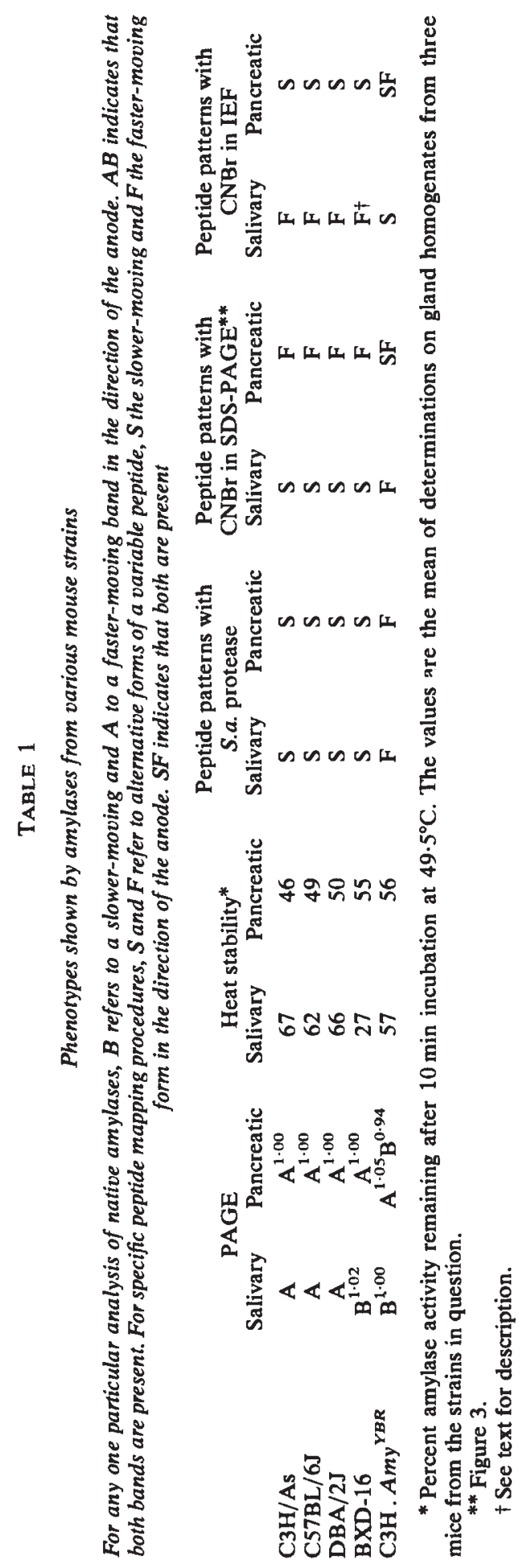


TABLE 2

Relative protein amounts and rate of synthesis of B-amylase from the strain BXD-16 as a fraction of the total $A$ - and B-amylase in heterozygotes to the A-amylase strains $D B A / 2 J$, $C 57 B L / 6 J$, and $C 3 H / A s$. The number of heterozygotes analyzed is given in brackets

\begin{tabular}{lcccc} 
& \multicolumn{2}{c}{$\begin{array}{c}\text { From isoproterenol } \\
\text { induced saliva }\end{array}$} & \multicolumn{2}{c}{$\begin{array}{c}\text { From pulse } \\
\text { labelled glands }\end{array}$} \\
Heterozygote & $\bar{x}$ & $S D$ & $\bar{x}$ & $S D$ \\
DBA/BXD-16 & $0.466(8)$ & 0.029 & $0.486(7)$ & 0.013 \\
C57BL/BXD-16 & $0.444(7)$ & 0.012 & $0.481(8)$ & 0.019 \\
C3H/BXD-16 & - & - & $0.473(4)$ & 0.010
\end{tabular}

\section{DisCusSION}

The present studies have demonstrated that $A m y^{\mathrm{BXD} 16}$ directs the synthesis of one structurally homogeneous salivary amylase in an amount equivalent to that in the progenitor strains, and this amylase has the same size and enzymatic activity as found for other mouse strains. The amylase differs from that of the progenitor strains by a lower electrophoretic mobility, by a lower negative net charge of one or more peptides produced by $\mathrm{CNBr}$ digestion, and by a lower heat stability.

The origin of $A m y^{\mathrm{BXD} 16}$ is apparently not from a non-progenitor strain, because admixture of non-progenitor genes could not be demonstrated and no other strain could be found with the same variant amylase complex. The complex is therefore most likely derived by a genetic alteration of a progenitor amylase complex. For other genes, the frequency of such alterations is below $10^{-4}$ per gene per generation. That BXD-16 was the only strain with non-progenitor amylase type out of $130 \mathrm{RI}$ strains, representing a total of $\mathbf{3 6 4 0}$ gene transmissions, makes the origin by a genetic alteration probable. Given also the fact that $d b^{4 J}$ and the amylase variant are genetically independent, it is most likely that the variant has arisen as the result of only one single genetic event. Four different genetic possibilities for the cause of the variant will be evaluated. (1) The appearance of a duplication or the breakdown of an existing duplication will not explain the variant type because the structural information does not necessarily change by such an event. Moreover, an alteration in the amount of gene product might be expected from such a change in gene dosage and this was not observed for the variant. (2) Recombination between the salivary amylase alleles in C57BL/6J and DBA/2J may have occurred during the inbreeding of BXD-16. However, it is unlikely that this would have given rise to the variant since identical isoelectric focusing patterns of $\mathrm{CNBr}$-peptides were found for the amylases of the progenitor strains and no combination of bands from the two strains would produce the pattern seen for BXD-16. (3) Reactivation of a silent gene (pseudogene) as the origin of the variant is unlikely because it would require that the previously active gene was inactivated by the same event and that the genetic information about amylase structure and quantity in the previously silent gene was very similar to the original gene. (4) A missense mutation in a salivary amylase gene in one of the progenitors seems to explain all the findings and thus to be the most likely origin of the variant. Conclusive evidence for this explana- 
tion may be produced by determining the primary structure of the variant protein and this work is now in progress.

Given that a single missense mutation is the most likely origin of the BXD-16 amylase variant and that all the salivary amylase produced is of the variant type, whereas the pancreatic amylase remains unaltered, then only one structural gene for salivary amylase is expressed in the strain BXD-16 and this is different from the genetic information for pancreatic amylase. Consequently at least one of the progenitor strains must also have just one salivary amylase gene. However, since the two progenitor strains and $\mathrm{C} 3 \mathrm{H} / \mathrm{As}$ all produce very comparable amounts of the amylase, it is likely that all three of them have only one salivary amylase gene.

Genetic alteration of known amylase complexes as implied from the present study for $A m y^{\text {BXD16 }}$, presents a new approach to the investigation of the structure of the amylase complex. In this case, the implications regarding the structure are in agreement with earlier studies of both quantity and structural heterogeneity of the amylase protein, and later studies of the base sequences of the relevant mRNA's and cloned DNA's (see Introduction). The present results emphasize that RI lines, by their controlled origin and breeding, represent valuable tools also for mutation studies, since each of them represents large numbers of gene transmissions.

Acknowledgments. - This work was supported by grants No. 511-15513 and 11-9359 from the Danish Natural Science Research Council.

The author is greatly indebted to B. A. Taylor for inspiration and criticism, and for providing laboratory space and RI lines during his visit to The Jackson Laboratory. The supply for mouse strains from M. Cherry, E. Eicher, P. Lane, T. Roderick, and E. Russell at The Jackson Laboratory and from J. T. Nielsen at the Institute of Ecology and Genetics, Aarhus, is much appreciated. The competent technical assistance of Mrs M. Clark is gratefully acknowledged.

\section{REFERENCES}

BLOOR, J. H., MEISLER, M. M., AND NIELSEN, J. T. 1981. Genetic determination of amylase synthesis in the mouse. J. Biol. Chem., 256, 373-377.

CLARKE, J. T. 1964. Simplified "disc" (polyacrylamide gel) electrophoresis, Ann. N. Y. Acad. Sci., 121, 428-436.

EICHER, E. M., AND LANE, P. W. 1980. Assignment of LG XVI to chromosome 3. J. Heredity, $71,315-318$.

HAGENBÜCHLE, O., BOVEY, R., AND YOUNG, R. A. 1980. Tissue-specific expression of mouse $\alpha$-amylase genes: Nucleotide sequence of isoenzyme mRNAs from pancreas and salivary gland. Cell, 21, 179-187.

HJORTH, J. P. 1979. Genetic variation in mouse salivary amylase rate of synthesis. Biochem. Genet., 17, 665-682.

HJORTH, J. P., LUSIS, A. J., AND NIELSEN, J. T. 1980. Multiple structural genes for mouse amylase. Biochem. Genet. 18, 281-302.

HJORTH, J. P. 1980. Mouse News Letter, 62, 41.

MACDONALD, R. J., CRERAR, M. M., SVAIN, W. F., PICTET, R. L., THOMAS, G., AND RUTTER, W. J. 1980. Structure of a family of rat amylase genes. Nature, 287, 117-122.

NIELSEN, J. T., AND SICK, K. 1975. Genetic polymorphism of amylase isoenzymes of the house mouse. Hereditas, 79, 279-286.

OWERBACH, D., AND HJORTH, J. P. 1980. Inheritance of a parotid secretory protein in mice and its use in determining salivary amylase quantitative variants. Genetics, 95, 129-141.

OWERBACH, D., NIELSEN, J. T., AND RUTTER, W. J. 1981. On the mechanism of variation of pancreatic amylase levels in mouse strains. J. Biol. Chem., 256, 6502-6506. 
SCHIBleR, U., TOSI, M., PITTET, A.-C., FABIANI, L., AND WEllaueR, P. K. 1980. Tissuespecific expression of mouse $\alpha$-amylase genes. J. Mol. Biol. 142, 93-116.

SICK, K., AND NIELSEN, J. T. 1964. Genetics of amylase isoenzymes in the mouse. Hereditas, 51, 291-296.

TAYLOR, B. A. 1981. Recombinant inbred strains. In Genetic Variants and Strains of the Laboratory Mouse, ed. M. Green. Gustav Fischer Verlag, Stuttgart (in press).

YOUNG, R. A., HAGENBÜCHLE, O., AND SCHIBLER, U. 1981. A single mouse $\alpha$-amylase gene specifies two different tissue-specific mRNAs. Cell, 23, 451-458. 